\title{
Microtubule Associated Protein
}

National Cancer Institute

\section{Source}

National Cancer Institute. Microtubule Associated Protein. NCI Thesaurus. Code C16861.

Proteins associated with the microtubule assembly infrastructure. These proteins include specialized motor proteins (dynein and kinesin) and smaller tubulin-crosslinking proteins (tau proteins). The proteins are required for both microtubule assembly and stabilization. 